\title{
OPEN Biogenic selenium nanoparticles (SeNPs) from citrus fruit have anti-bacterial activities
}

\author{
Ghalia Batool Alvi ${ }^{1}$, Muhammad Shahid Iqbal' ${ }^{2}$ Mazen Mohammed Saeed Ghaith ${ }^{3}$, \\ Abdul Haseeb ${ }^{4}$, Bilal Ahmed ${ }^{5}$ \& Muhammad Imran Qadir ${ }^{1 凶}$
}

Nanotechnology deals with the synthesis of materials and particles at nanoscale with dimensions of 1-100 nm. Biological synthesis of nanoparticles, using microbes and plants, is the most proficient method in terms of ease of handling and reliability. Core objectives of this study were to synthesize metallic nanoparticles using selenium metal salt from citrus fruit extracts, their characterization and evaluation for antimicrobial activities against pathogenic microbes. In methodology, simple green method was implicated using sodium selenite salt solution and citrus fruit extracts of Grapefruit and Lemon as precursors for synthesizing nanoparticles. Brick red color of the solution indicated towards the synthesis of selenium nanoparticles (SeNPs). Nanoparticle's initial characterization was done by UV-Vis Spectrophotometry and later FTIR analysis and DLS graphs via Zetasizer were obtained for the confirmation of different physical and chemical parameters of the nanoparticles. Different concentrations of SeNPs were used for antimicrobial testing against $E$. coli, M. luteus, B. subtilis and $K$. pneumoniae comparative with the standard antibiotic Ciprofloxacin. SeNPs possessed significant antimicrobial activities against all the bacterial pathogens used. Conclusively, SeNPs made from citrus fruits can act as potent antibacterial candidates.

From last few decades, Nanotechnology has become the most promising and advancing field because of its wide applications in applied sciences and technology ${ }^{1}$. In order to synthesize nanoscale materials, by using any biological source, nanotechnology is considered as emerging technical tool for their ecofriendly synthesis ${ }^{2}$. Nanoparticles display distinctive characteristics because of their high surface energy and large surface to volume ratio $^{3}$. Metallic nanoparticles are very popular for their wide range of applications in different areas of science including physics, chemistry, material and biomedical sciences. They have numerous applications in optoelectronics, catalysis and diagnostic biological devices ${ }^{2}$. The size and properties of every nanoparticle vary depending upon the synthesis methods of nanoparticles and their source.

Synthesizing nanoparticles with different chemical composition, size and controlled mono-dispersity has become areas of research in nanotechnology ${ }^{4}$. Synthesis of nanoparticles can be carried out by various means for example physical, chemical and biological methods. Biological based synthesis using plants and their extracts, enzymes and microbes is considered as the most ecofriendly alternative to physical and chemical methods. Using plant-based synthesis methods are beneficial over other biological procedures as they eliminate the complex process of cell culture maintenance ${ }^{5}$.

Selenium is well known for its semiconductor and photoelectric properties. It also has great potential in the field different fields of science including medicine, biology, physics and chemistry. Selenium nanoparticles possess good adsorptive and biological activity because of interaction between nanoparticles and different functional groups (C-O, C-N. NH and COO-) of proteins ${ }^{6}$. These nanoparticles also exhibit antimicrobial, anticancer, antioxidant and enzyme inhibition activities but preparation of stable selenium nanoparticles is bit tricky ${ }^{7}$. Number of different plant extracts, microorganisms and enzymes has been utilized as a source for production of Selenium nanoparticles of variable size and morphology. Nano-sized Selenium particles are used for huge number of applications because of their advantageous features over bulk form for example low dosage, low toxicity and better reactivity ${ }^{3}$.

\footnotetext{
${ }^{1}$ Institute of Molecular Biology and Biotechnology, Bahauddin Zakariya University, Multan, Pakistan. ${ }^{2}$ Department of Clinical Pharmacy, College of Pharmacy, Prince Sattam Bin Abdulaziz University, Al-kharj 11942, Saudi Arabia. ${ }^{3}$ Department of Laboratory Medicine, Faculty of Applied Medical Sciences, Umm Al-Qura University, Makkah, Saudi Arabia. ${ }^{4}$ Department of Clinical Pharmacy, College of Pharmacy, Umm Al-Qura University, Al-Abdia Campus, Taif Road, PO Box 13574, Makkah 21955, Saudi Arabia. ${ }^{5}$ School of Pharmacy, Nanjing Medical University, Nanjing, Jiangsu Province, People's Republic of China. ${ }^{\circledR}$ email: mrimranqadir@hotmail.com
} 

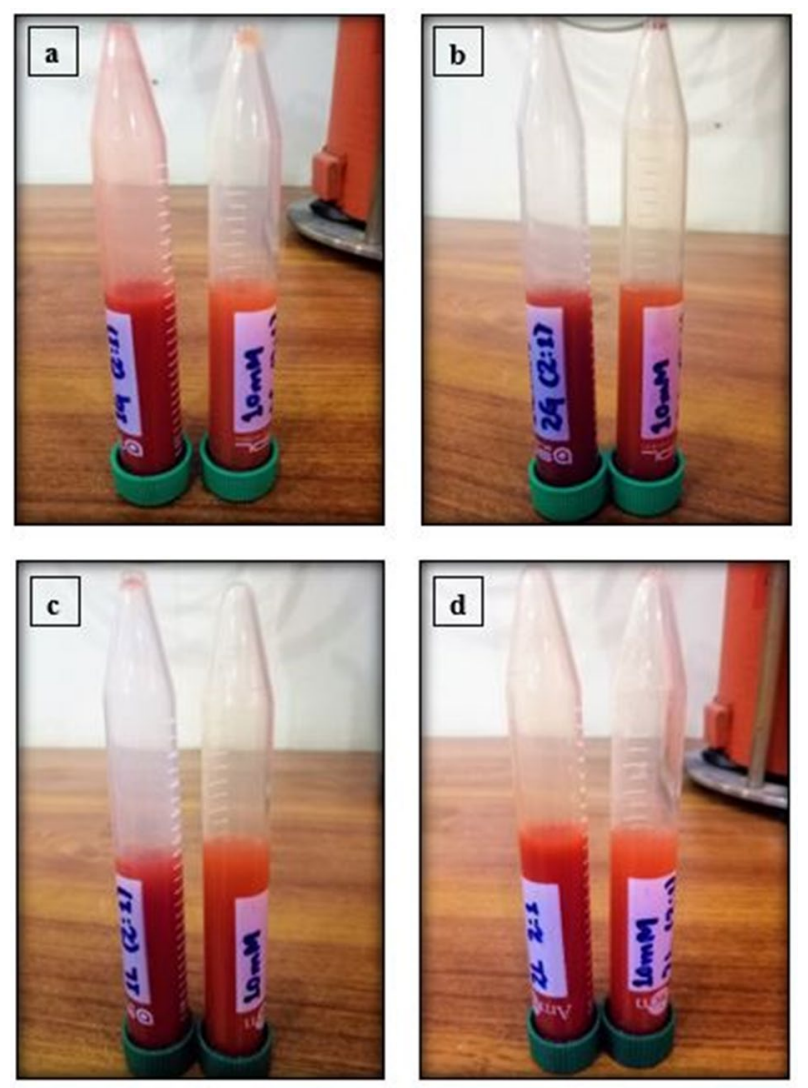

Figure 1. SeNPs synthesized from citrus fruit extracts; (a) from Citrus paradisi fresh juice extract, (b) from Citrus limonFresh juice extract, (c) from Citrus paradisi fresh peels extract and (d) from Citrus limon fresh peel extract.

Citrus are the fruits belonging to genus. There are several instances of their reported antimicrobial activity ${ }^{8}$. Few other activities like antiviral, uricosuric, larvicidal, anti-hepatotoxic, anti-yeast and antimutagenic have been reported by citrus fruits. The antimicrobial activity of citrus has been found to be present due to a number of reasons like presence of volatile oily compounds, essential oils and various flavonoids. They have been widely employed for synthesizing metallic nanoparticles because of their notable activities. Citrus fruits have been selected as a source for Selenium nanoparticles synthesis because of their promising antibacterial properties ${ }^{9}$.

The objective of the current study was to synthesize selenium nanoparticles from citrus fruit i.e. Citrus limon (lemons) and Citrus paradise (grapefruits) extracts, their general characterization and their assessment for antibacterial activities against various pathogens.

\section{Results}

Selenium nanoparticles (SeNPs) synthesized from citrus fruits extracts via Biological method of nanoparticles synthesis are shown in Fig. 1.

UV-Vis Spectrophotometry was performed for all the synthesized SeNPs from citrus fruits extracts and the synthesized SeNPs showed maximum absorption peaks between the range of 400-600 nm wavelength at absorbance of about 1.5-2. SeNPs synthesized from Citrus paradisi (Grapefruit) fresh juice extract showed the absorbance peaks at $350 \mathrm{~nm}$ and $500 \mathrm{~nm}$ while SeNPs synthesized from Citrus paradisi (Grapefruit) fresh peels extract displayed absorbance at $345 \mathrm{~nm}$ and $550 \mathrm{~nm}$ which is clearly demonstrated in the Fig. 2a,b respectively. In the same context, SeNPs that were synthesized using fresh juice extract of Citrus limon (Lemon) showed absorbance peaks at $300 \mathrm{~nm}$ and $500 \mathrm{~nm}$ whereas SeNPs synthesized from fresh peel extract of Citrus limon (Lemon) showed absorbance peaks at wavelengths of $350 \mathrm{~nm}$ and $550 \mathrm{~nm}$ clearly shown in Fig. 3a,b respectively.

Antimicrobial activity of the synthesized SeNPs from different fruit extracts were evaluated through agar well diffusion method against bacterial pathogens comparative to the standard antibiotic Ciprofloxacin. The clear ZOIs of the synthesized SeNPs are shown in the figures and their values are described in the tables. ZOIs of SeNPs synthesized by Citrus paradisi fresh juice extract are displayed in Fig. 4.

Antimicrobial activities of SeNPs synthesized from the Citrus fruit are given in Tables 1, 2, 3 and 4. Figures 5, 6 and 7 are the representation of Zone of inhibitions (ZOIs) of the synthesized SeNPs. SeNPs synthesized from Lemon extracts with $12 \mathrm{mM}$ Sodium selenite concentration exhibits highest antimicrobial activity against bacterial pathogens specifically against $E$. coli and K. pneumoniae with ZOI of $25 \mathrm{~mm}$. So, further characterization tests were performed for that sample of SeNPs. Results were statistically analyzed. The mean value and the standard deviation of all the replicates were calculated. The nanoparticles synthesized from both the citrus fruits were 

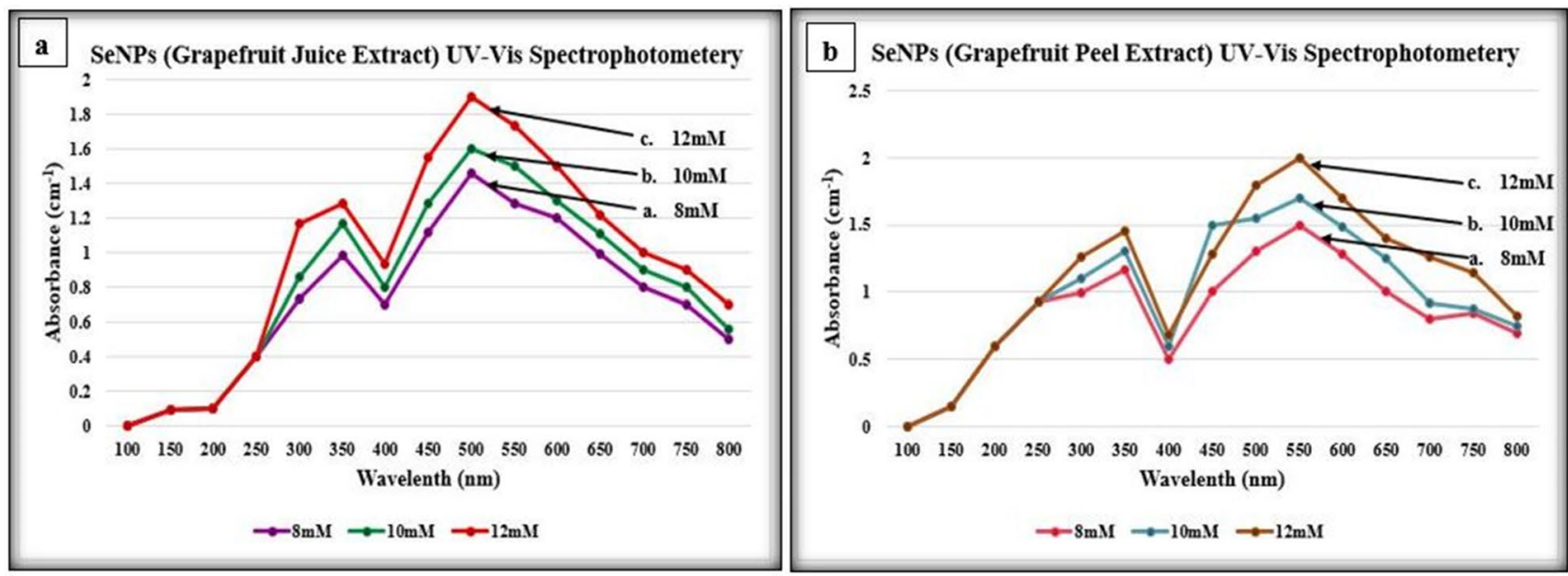

Figure 2. UV-Vis spectrophotometry analysis of SeNPs synthesized from Citrus paradisi (Grapefruit); (a) fresh juice extract, (b) fresh peels extract.
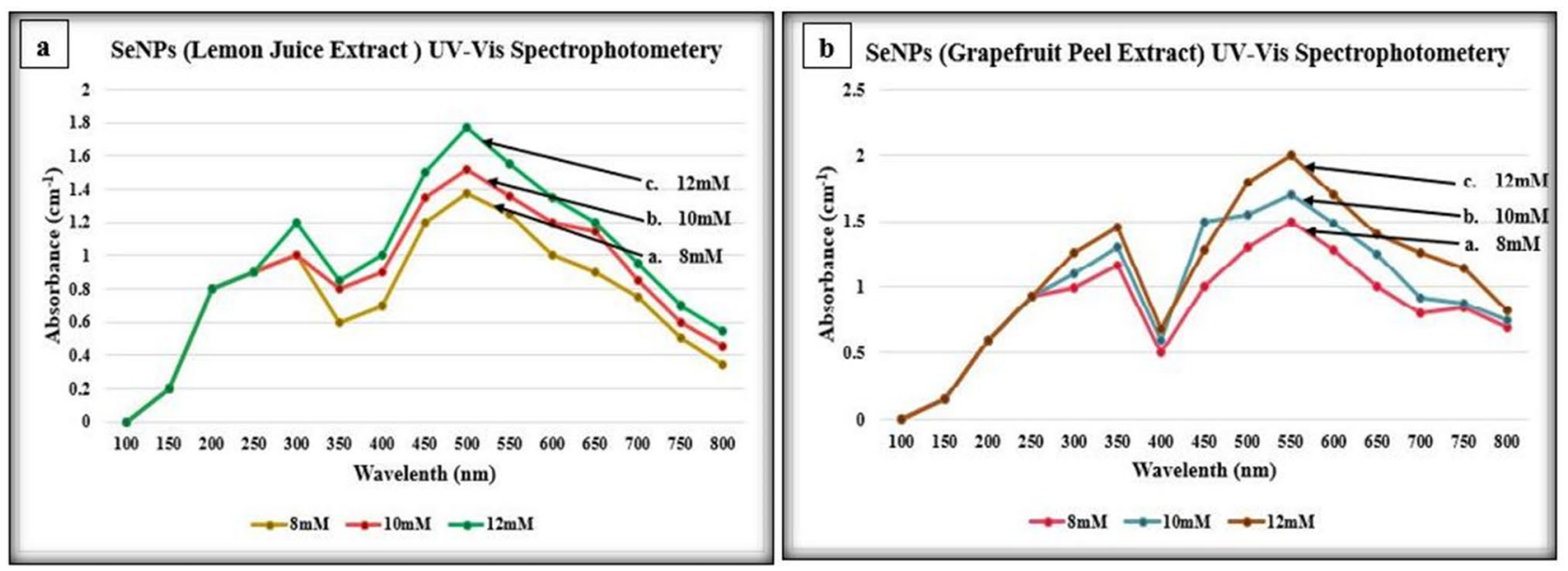

Figure 3. UV-Vis spectrophotometry analysis of SeNPs synthesized from Citrus limon (Lemon); (a) fresh juice extract, (b) fresh peels extract.

compared for their antibacterial activity. The resultant ( $\mathrm{p}$ value less than 0.05) of t-test to compared two citrus fruits for their activity (Citrus limon and Citrus paradisi) have statistical differences. Citrus limon has a better activity. The p-value $<0.05$ was considered as significant. The results confirmed that SeNPs synthesized from Citrus limon (Lemon) fresh peels extract showed antimicrobial activity comparable with Standard (Ciprofloxacin) with $\mathrm{p}<0.05$.

Fourier Transform Infra-Red (FTIR) Spectroscopy was performed using FTIR spectrometer for the detection and presence of functional groups involved in the selenium nanoparticle synthesis. Wavelength absorbance reading of Infra-red radiations was checked [for SeNPs synthesized from Citrus limon (Lemon) peels extract] between the range of 1000-3500 $\mathrm{cm}^{-1}$. Figure 8 displayed the two absorbance peaks for SeNPs synthesized from Citrus limon (Lemon) fresh peels extract at $3274.74 \mathrm{~cm}^{-1}$ and $1637.05 \mathrm{~cm}^{-1}$. The peak between 3200 and $3300 \mathrm{~cm}^{-1}$ confirmed the presence of $\mathrm{O}-\mathrm{H}$ bonded stretching and strong vibrations due to presence of alcohol and phenol functional groups. $\mathrm{N}-\mathrm{H}$ stretching of Amide A in proteins was also detected in that region. Similarly, for the peak in the region of $1600-1700 \mathrm{~cm}^{-1}, \mathrm{C}=\mathrm{C}$ stretching, $\mathrm{C}-\mathrm{N}$ stretching and Amides functional groups of amides I \& II with $\mathrm{C}-\mathrm{H}$ bonds with the presence of alkenes.

Zetasizer was used for the determination of size of the synthesized SeNPs exhibiting highest antimicrobial activity against all the bacterial pathogens i.e. SeNPs synthesized from Lemon peel extract, using Dynamic light scattering (DLS) phenomena. DLS measures the hydrodynamic volume of the particles. Figure 9 represents the Dynamic Light Scattering Analysis (DLS) through Zetasizer. On the $\mathrm{x}$-axis there was hydrodynamic diameter the SeNPs as diameter in nanometer (d.nm), while on y-axis values for scattering intensity from the particles were plotted. The test sample of the SeNPs synthesized from Citrus limon (Lemon) Peels extract was analyzed for measuring its size through dynamic light scattering phenomena. A graph was obtained with one visible peak within a range of $1100-3500 \mathrm{~nm}$ (diameter). The maximum peak was observed at $1527 \mathrm{~d} . \mathrm{nm} / 100.0 \%$. The 

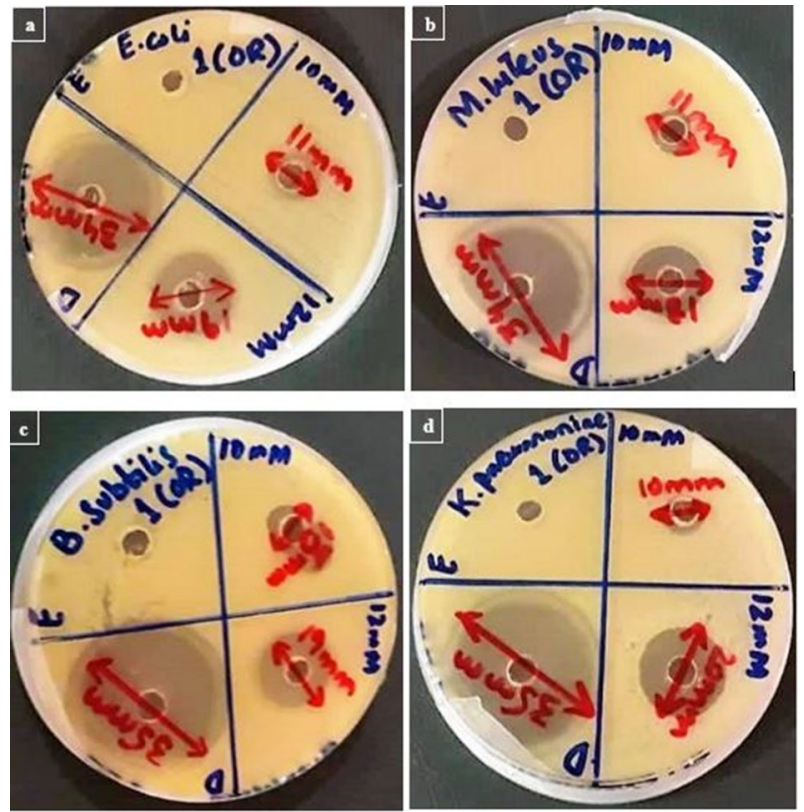

Figure 4. Antimicrobial activity analysis of SeNPs synthesized from Citrus paradisi (Grapefruit) fresh juice extract against bacterial pathogens; (a) E. coli, (b) M. luteus, (c) B. subtilis, (d) K. pneumoniae.

\begin{tabular}{|l|l|l|l|l|l|}
\hline Standard and sample & Replicates & E. coli & M. luteus & B. subtilis & K. pneumoniae \\
\hline \multirow{5}{*}{ Standard drug } & R1 & 34.6 & 33.9 & 35 & 33.9 \\
\cline { 2 - 6 } & R2 & 34.8 & 34.2 & 35.2 & 34.8 \\
\cline { 2 - 6 } & R3 & 32.6 & 33.9 & 34.8 & 36.3 \\
\cline { 2 - 6 } & Mean \pm SD & $34 \pm 1.216$ & $34 \pm 0.173$ & $35 \pm 0.200$ & $35 \pm 1.212$ \\
\hline \multirow{5}{*}{$10 \mathrm{mM}$} & R1 & 11.6 & 11.8 & 14.6 & 10.4 \\
\cline { 2 - 6 } & R2 & 10.2 & 10.2 & 12.4 & 8.9 \\
\cline { 2 - 6 } & R3 & 11.2 & 11 & 12 & 10.7 \\
\cline { 2 - 6 } & Mean \pm SD & $11 \pm 0.721$ & $11 \pm 0.800$ & $13 \pm 1.400$ & $10 \pm 0.964$ \\
\hline R1 & 20.2 & 17.7 & 20 & 21.9 \\
\cline { 2 - 6 } & R2 & 19 & 19.3 & 19.6 & 19.1 \\
\cline { 2 - 6 } & R3 & 17.8 & 17 & 17.4 & 19 \\
\cline { 2 - 6 } & Mean \pm SD & $19 \pm 1.200$ & $18 \pm 1.178$ & $19 \pm 1.400$ & $20 \pm 1.646$ \\
\hline
\end{tabular}

Table 1. Zone of inhibition ( $\mathrm{mm}$ ) of SeNPs synthesized from Citrus paradisi (Grapefruit) fresh juice extract in comparison with the standard drug and control extract against bacterial pathogens. p-value $<0.05$.

average Zeta size of the synthesized SeNPs was about 4462 d.nm and its PDI (polydispersion index) value was 0.127 with PDI width of $1588 \mathrm{~d}$. nm.

\section{Discussion}

The basic objective of this study was the biogenic synthesis of SeNPs from two citrus species, i.e., Citrus paradisi and Citrus limon and their further analysis as potential antibacterial agents. The primary reason for selecting two citrus species is to find out which performs best against bacterial species. Naturally citrus fruits are known to have several nutritional compounds. Other than these beneficial phytochemicals and phenolic compounds, they are known to possess several biological properties ${ }^{10}$. In the present era, antimicrobial infections are the most common threat to human health. The use of antibiotics can cure bacterial infections, but their frequent use makes bacteria resistant against such antibiotics. The need of developing new antibacterial drugs is the need of present time. Selenium also possesses several biomedical applications. Selenium nanoparticles synthesized from citrus fruits can amplify the biomedical properties of both selenium and citrus fruits.

Several researchers have synthesized selenium nanoparticles using leaves of citrus plants, but we have adopted the biological method for synthesizing SeNPs from Citrus paradisi and Citrus limon ${ }^{3}$. The bacterial strains against which antibacterial property of the nanoparticles were tested can pose a major threat to human health. In this research, SeNPs were synthesized using fresh juice and peel extracts of grapefruit and lemon. Two parts of the fruit extract and one part of the salt solution was mixed. The solution after incubation for the optimum time 


\begin{tabular}{|l|l|l|l|l|l|}
\hline Standard and sample & Replicates & E. coli & M. luteus & B. subtilis & K. pneumoniae \\
\hline \multirow{5}{*}{ Standard drug } & R1 & 34.8 & 36.1 & 33.6 & 33.8 \\
\cline { 2 - 6 } & R2 & 33.9 & 35.8 & 34.2 & 35.1 \\
\cline { 2 - 6 } & R3 & 33.3 & 33.1 & 34.2 & 33.1 \\
\cline { 2 - 6 } & Mean \pm SD & $34 \pm 0.754$ & $35 \pm 1.652$ & $34 \pm 0.346$ & $34 \pm 1.014$ \\
\hline \multirow{4}{*}{$10 \mathrm{mM}$} & R1 & 13.5 & 9.9 & 12.4 & 13 \\
\cline { 2 - 6 } & R2 & 12 & 10.1 & 10.8 & 12.7 \\
\cline { 2 - 6 } & R3 & 10.5 & 10 & 12.8 & 13.3 \\
\cline { 2 - 6 } & Mean \pm SD & $12 \pm 1.500$ & $10 \pm 0.100$ & $12 \pm 1.058$ & $13 \pm 0.300$ \\
\hline \multirow{5}{*}{$\mathrm{mM}$} & R1 & 21.4 & 19.3 & 18.8 & 20 \\
\cline { 2 - 6 } & R2 & 20.1 & 20.2 & 19.2 & 21.6 \\
\cline { 2 - 6 } & R3 & 18.5 & 20.5 & 19 & 18.4 \\
\cline { 2 - 6 } & Mean \pm SD & $20 \pm 1.452$ & $20 \pm 0.624$ & $19 \pm 0.200$ & $20 \pm 1.600$ \\
\hline
\end{tabular}

Table 2. Zone of inhibition ( $\mathrm{mm}$ ) of SeNPs synthesized from Citrus paradisi (Grapefruit) fresh peels extract in comparison with the standard drug and control extract against bacterial pathogens. $\mathrm{p}$-value $<0.05$.

\begin{tabular}{|l|l|l|l|l|l|}
\hline Standard and sample & Replicates & E. coli & M. luteus & B. subtilis & K. pneumoniae \\
\hline \multirow{5}{*}{ Standard drug } & R1 & 36.4 & 35.8 & 37.3 & 35.6 \\
\cline { 2 - 6 } & R2 & 35.9 & 36.2 & 37.7 & 36.3 \\
\cline { 2 - 6 } & R3 & 35.7 & 36 & 36 & 36.1 \\
\cline { 2 - 6 } & Mean \pm SD & $36 \pm 0.360$ & $36 \pm 0.200$ & $37 \pm 0.888$ & $36 \pm 0.360$ \\
\hline \multirow{5}{*}{$10 \mathrm{mM}$} & R1 & 18 & 18.5 & 21.3 & 20 \\
\cline { 2 - 6 } & R2 & 17.4 & 19 & 20 & 19.2 \\
\cline { 2 - 6 } & R3 & 18.6 & 16.5 & 18.7 & 20.8 \\
\cline { 2 - 6 } & Mean \pm SD & $18 \pm 0.600$ & $18 \pm 1.322$ & $20 \pm 1.300$ & $20 \pm 0.800$ \\
\hline R1 & 25 & 21.6 & 24.2 & 25.2 \\
\cline { 2 - 6 } & R2 & 23.9 & 22 & 23.6 & 24 \\
\cline { 2 - 6 } & R3 & 23.1 & 22.4 & 24.2 & 22.8 \\
\cline { 2 - 6 } & Mean \pm SD & $24 \pm 0.953$ & $22 \pm 0.400$ & $24 \pm 0.346$ & $24 \pm 1.200$ \\
\hline
\end{tabular}

Table 3. Zone of inhibition ( $\mathrm{mm}$ ) of SeNPs synthesized from Citrus limon (Lemon) fresh juice extract in comparison with the standard drug and control extract against bacterial pathogens. p-value $<0.05$.

\begin{tabular}{|l|l|l|l|l|l|}
\hline Standard and sample & Replicates & E. coli & M. luteus & B. subtilis & K. pneumoniae \\
\hline \multirow{5}{*}{ Standard drug } & R1 & 39 & 37.6 & 38 & 36.2 \\
\cline { 2 - 6 } & R2 & 38.5 & 37.4 & 38.5 & 37.3 \\
\cline { 2 - 6 } & R3 & 39.5 & 39 & 37.5 & 37.5 \\
\cline { 2 - 6 } & Mean \pm SD & $39 \pm 0.500$ & $38 \pm 0.871$ & $38 \pm 0.500$ & $37 \pm 0.700$ \\
\hline \multirow{4}{*}{$10 \mathrm{mM}$} & R1 & 21.3 & 19.1 & 21 & 18.4 \\
\cline { 2 - 6 } & R2 & 22.4 & 19.8 & 20.2 & 19.8 \\
\cline { 2 - 6 } & R3 & 19.3 & 18.1 & 18.8 & 21.8 \\
\cline { 2 - 6 } & Mean \pm SD & $21 \pm 1.571$ & $19 \pm 0.854$ & $20 \pm 1.113$ & $20 \pm 1.708$ \\
\hline \multirow{5}{*}{$\mathrm{mM}$} & R1 & 26.2 & 21.7 & 24.2 & 26 \\
\cline { 2 - 6 } & R2 & 25.4 & 22 & 24.6 & 25.8 \\
\cline { 2 - 6 } & R3 & 23.4 & 22.3 & 23.2 & 23.2 \\
\cline { 2 - 6 } & Mean \pm SD & $25 \pm 1.442^{*}$ & $22 \pm 0.300$ & $24 \pm 0.721^{*}$ & $25 \pm 1.562^{*}$ \\
\hline
\end{tabular}

Table 4. Zone of inhibition ( $\mathrm{mm}$ ) of SeNPs synthesized from Citrus limon (Lemon) fresh peels extract in comparison with the standard drug and control extract against bacterial pathogens. ${ }^{*}$ p-value $<0.05$. 

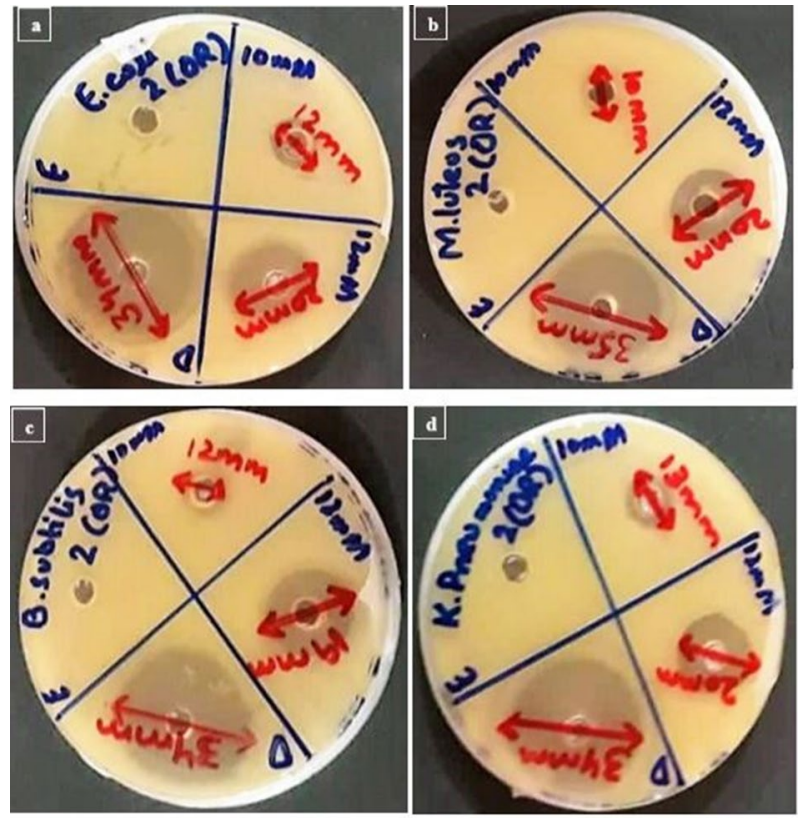

Figure 5. Antimicrobial activity analysis of SeNPs synthesized from Citrus paradisi (Grapefruit) fresh peels extract against bacterial pathogens; (a) E. coli, (b) M. luteus, (c) B. subtilis, (d) K. pneumoniae.
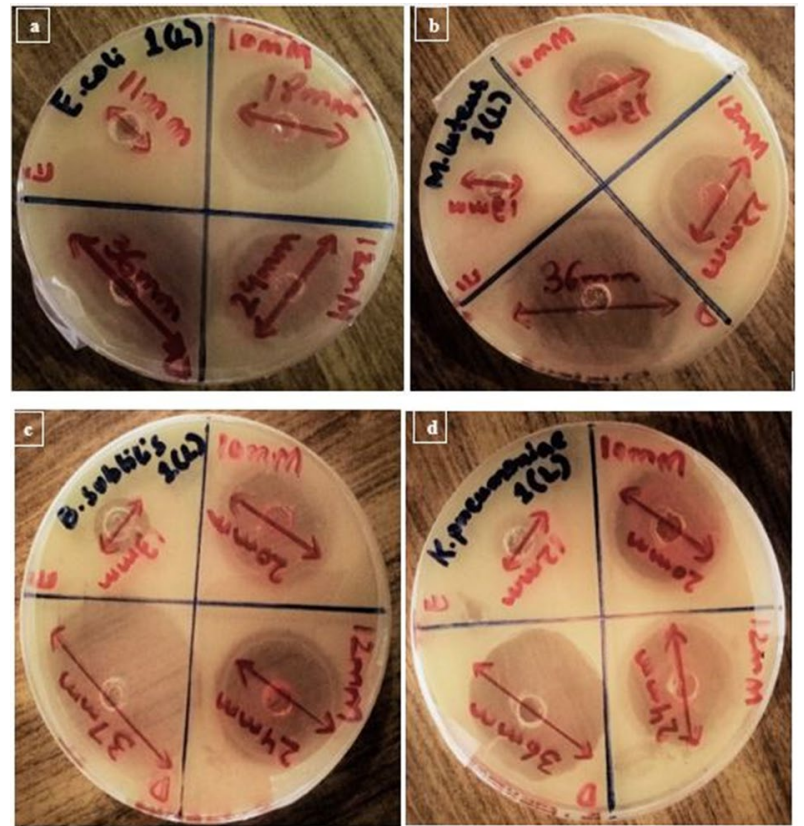

Figure 6. Antimicrobial activity analysis of SeNPs synthesized from Citrus limon (Lemon) fresh juice extract against bacterial pathogens; (a) E. coli, (b) M. luteus, (c) B. subtilis, (d) K. pneumoniae.

and temperature and after a visible color change from slight yellowish to bright brick red color confirmed the reduction of sodium selenite into SeNPs. A visible color change from light yellow to brick red color indicated the synthesis of SeNPs. Vyas and Rana ${ }^{4}$ synthesized SeNPs using Allium sativum extract. A similar color change from yellow to brick red was observed which confirmed the synthesis of selenium nanoparticles.

The synthesized SeNPs were then used for UV-Vis Spectrophotometer Analysis for the confirmation of the reduction of sodium selenite into SeNPs. The synthesized SeNPs from Citrus paradisi and Citrus limon showed absorbance peaks between a range of 300-550 nm. In a similar study of SeNP synthesis from Citrus limon leaves by KS Prasad and colleagues, the UV-Vis spectrophotometer analysis of the synthesized SeNPs was done between 250-750 $\mathrm{nm}$. The synthesized SeNPs exhibited absorbance peak at $395 \mathrm{~nm}^{3}$. 

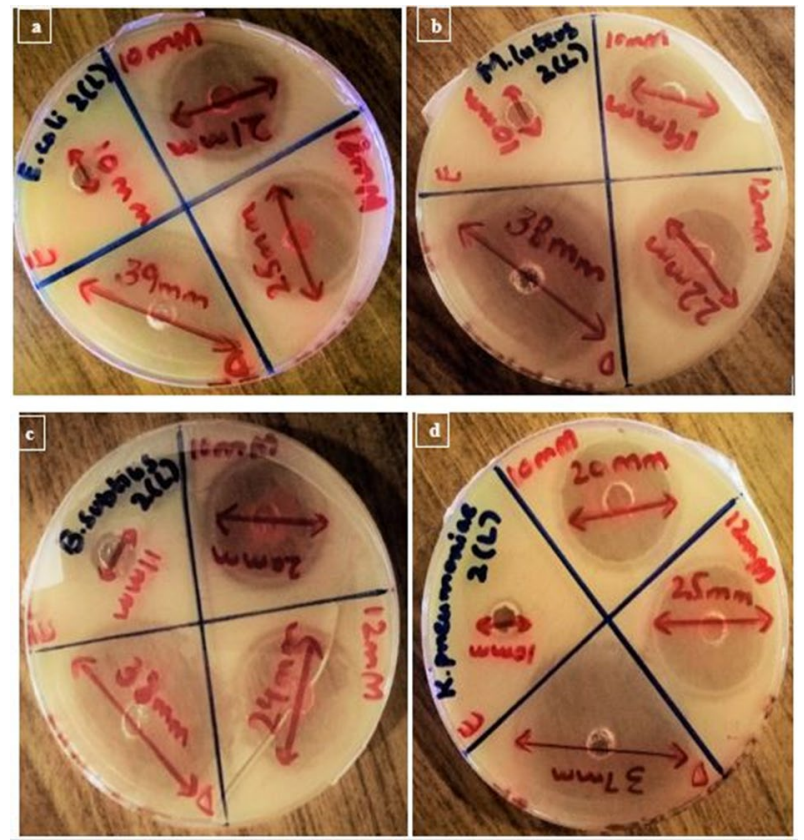

Figure 7. Antimicrobial activity analysis of SeNPs synthesized from Citrus limon (Lemon) fresh peels extract against bacterial pathogens; (a) E. coli, (b) M. luteus, (c) B. subtilis, (d) K. pneumoniae.

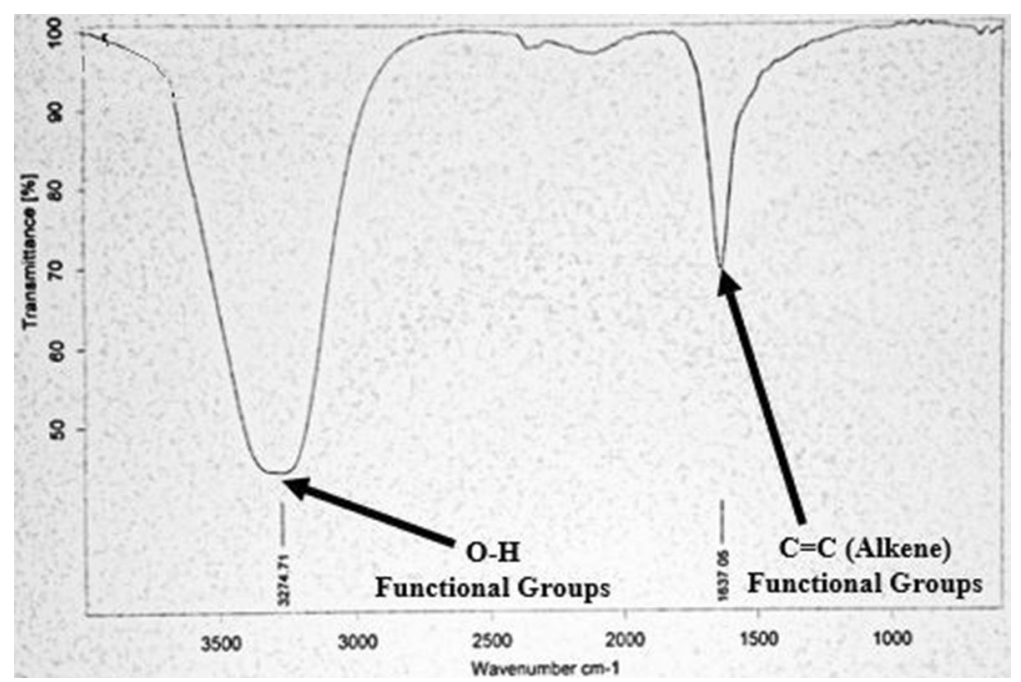

Figure 8. FTIR band spectrum study of SeNPs synthesized from Citrus limon (Lemon) fresh peels extract.

Then Functional groups involved in the reduction of sodium selenite into SeNPs were evaluated via FTIR spectroscopy of all the synthesized SeNPs. Absorbance reading of Infra-red radiations was checked for each sample between the ranges of $1000-3500 \mathrm{~cm}^{-1}$. All the samples of synthesized SeNPs in this study exhibited peaks between two ranges, i.e. $1600-1700 \mathrm{~cm}^{-1}$ and $3200-3300 \mathrm{~cm}^{-1}$. The absorbance peaks between 3200 and $3300 \mathrm{~cm}^{-1}$ confirmed the presence of $\mathrm{O}-\mathrm{H}$ bonded stretching and strong vibrations due to presence of alcohol and phenol functional groups. $\mathrm{N}-\mathrm{H}$ stretching of Amide $\mathrm{A}$ in proteins was also detected in that region. Similarly, for the peaks in the region of $1600-1700 \mathrm{~cm}^{-1}, \mathrm{C}=\mathrm{C}$ stretching, $\mathrm{C}-\mathrm{N}$ stretching and Amides functional groups of amides I \& II with C-H bonds with the presence of alkenes. Borna Fardsadegh and Hoda Jafarizadeh-Malmiri synthesized SeNPs from aloe vera leaf extract. The FTIR spectroscopy showed that the synthesized nanoparticles exhibited peaks at $1635.52 \mathrm{~cm}^{-1}$, and $3454.3 \mathrm{~cm}^{-1}$. The peak in region between $1600-1700 \mathrm{~cm}^{-1}$ confirmed the presence of amide group while the peak between 2900 and $3200 \mathrm{~cm}^{-1}$ represented the $\mathrm{O}-\mathrm{H}$ vibrations ${ }^{11}$.

In order to cope with the serious bacterial infections, the synthesized SeNPs were analyzed for antibacterial activity against harmful pathogens. The pathogens against which the synthesized SeNPs of this study tested were: E. coli, M. luteus, B. subtilis and K. pneumoniae. All these bacteria possess a serious threat to human health. Our synthesized SeNPs showed ZOI from 18 to $25 \mathrm{~mm}$. All the nanoparticle concentrations were tested in comparison 


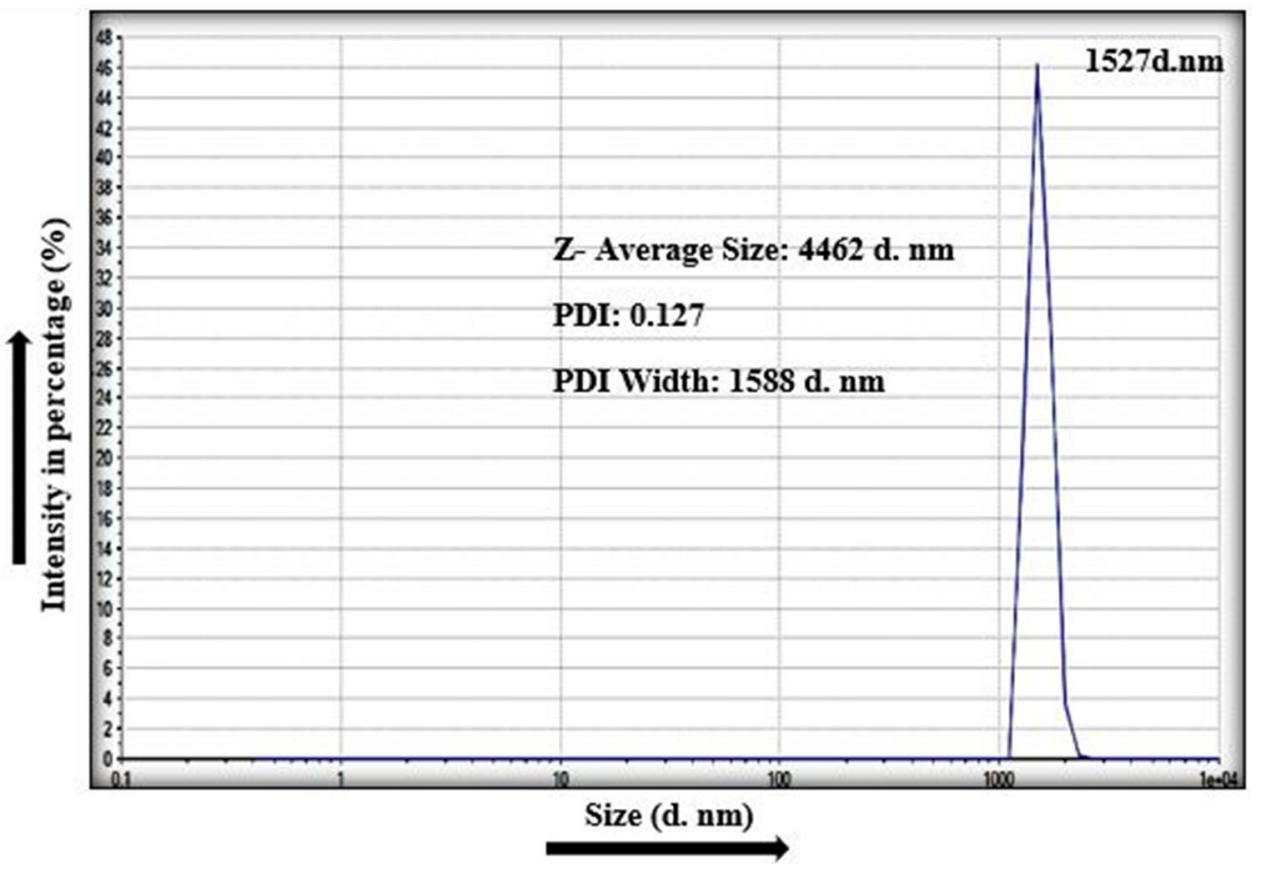

Figure 9. Dynamic light scattering study of SeNPs synthesized from Citrus limon (Lemon) fresh peels extract.

with the standard antibiotic drug ciprofloxacin. The maximum ZOI was showed by $12 \mathrm{mM}$ concentration SeNPs from fresh lemon peel extract against E. coli and K. pneumoniae. The maximum zone is $25 \mathrm{~mm}$. Many researchers have synthesized selenium nanoparticles but the antimicrobial activity of SeNPs from lemon (fresh juice \& fresh peel) and grapefruit (fresh juice \& fresh peel) against harmful bacterial pathogens in this manuscript correspond to a novel research. This research also supported the fact that SeNPs synthesized from citrus fruits especially lemon can act as potential antibacterial agents in the coming future.

SeNPs which showed highest antimicrobial activity, i.e. SeNPs synthesized from Citrus limon (Lemon) fresh peels extract were further used for the size determination via Zetasizer and Dynamic Light Scattering (DLS). A graph was obtained with one visible peak within a range of 1100-3500 d.nm. The maximum peak was observed at $1527 \mathrm{~d} . \mathrm{nm} / 100.0 \%$. The size measure through dynamic light scattering is actually a bit larger than the actual size of the nanoparticles. The reason for the large measured size of the nanoparticles is due to the fact that DLS measures the hydrodynamic volume of the particle in aqueous state ${ }^{12}$. Sometime the particles in the liquid medium form aggregates. That's why DLS phenomena measures the size of the aggregates rather than measuring the size of single nanoparticle ${ }^{13}$. Generally, PDI value ranges from 0 to 1 . The particles with PDI from 0 to 0.08 are monodisperse sized particles, $0.08-0.7$ is the middle range of particle size while $0.7-1$ PDI value shows the polydispersity of the particle sizes. The particle synthesized in this study exhibited PDI value in range of $0.08-0.7$ and PDI value under 0.3 is considered as the accepted or prioritized value in case of pharmaceutical NPs. Garima Sharma and colleagues synthesized SeNPs from dried Vitis vinifera (raisin) extract and used the DLS technique to measure the size of the synthesized nanoparticles ${ }^{12}$.

\section{Conclusion}

Nanotechnology is the branch of science which deals with the dimensions in range of nanoscale. Nanoparticles can be produced from ceramics, polymers, metals etc. There are different types of metallic nanoparticles including Gold, Silver, Copper, Iron, Selenium and many others. Biological synthesis of SeNP can be done by bacteria, fungi, and plants (Green Synthesis). Green synthesis usually involves the amalgamation of Selenium salt solution with plant extracts to produce Nanoparticles. In this study, the antimicrobial activity of Citrus fruits extracts based SeNPs was analyzed. Citrus limon and Citrus paradisi were used as green source. Green synthesis methodology was used in this synthesis, and the color change to brick red was selected as an initial indicator of SeNPs synthesis. The confirmation and characterization tests of these SeNPs were performed. These tests involved UV Visible Spectrophotometer analysis, FTIR spectroscopy and Zetasizer analysis through Dynamic Light Scattering (DLS). After the confirmation of SeNPs synthesis, antimicrobial activities were checked against four bacterial cultures, E. coli, K. pneumoniae, M. leteus, and B. subtilis. The activity of SeNPs was compared with a standard antibiotic (Ciprofloxacin). The results showed that selenium nanoparticles synthesized from citrus fruits (Citrus paradisi and Citrus limon) possess notable antibacterial activities. They can act as a potential candidate for making promising antibacterial drugs as a replacement of antibiotics. 


\section{Materials and methods}

Sample collection. Citrus fruits i.e. Citrus limon (lemons) and Citrus paradise (grapefruits) were purchased from Local fruit market of Pakistan while metal salt; Sodium selenite $\left(\mathrm{Na}_{2} \mathrm{SeO}_{3}\right)$ was purchased from Sigma Aldrich distributions.

Biosynthesis of selenium nanoparticles (SeNPs). Fruit and peel extract preparation. Fruits samples were thoroughly washed with distilled and double distilled water to remove impurities and dust particles followed by drying of fruits with sterilized paper towels. Fruits were cut down using sterilized knife and fresh juice extracts of Citrus limon and Citrus paradisi were prepared by directly squeezing the juice out of fruit and then it was filtered through muslin cloth ${ }^{14}$ followed by centrifugation at $5000 \mathrm{rpm}$ for $20 \mathrm{~min}$ at RT. The resultant supernatant was separated from the pellet in labelled sterilized glass media bottles and stored at $4{ }^{\circ} \mathrm{C}$ for further use extracts ${ }^{5,15,16}$. In the same context fresh peel extracts were prepared firstly by peeling the citrus fruits and then using sterilized knife, their peels were cut down into small pieces. About $70 \mathrm{~g}$ of the fresh peels were added in $300 \mathrm{~mL}$ of the double distilled water and boiled for 10-20 min in a water bath ${ }^{9,17}$. After boiling the peel extract was filtered through a series of Whatman filter papers with different pore sizes and the resultant filtrate was stored at $4^{\circ} \mathrm{C}$ in labelled sterilized glass media bottles ${ }^{18-20}$.

Sodium selenite $\left(\mathrm{Na}_{2} \mathrm{SeO}_{3}\right)$ salt solution preparation. For preparing sodium selenite solution, firstly a $1 \mathrm{M}$ stock solution was prepared in $50 \mathrm{~mL}$ and from that stock solution further dilutions of $8 \mathrm{mM}, 10 \mathrm{mM}$ and $12 \mathrm{mM}$ were prepared which were used for nanoparticle synthesis.

Synthesis of selenium nanoparticles (SeNPs). Sodium Selenite $\left(\mathrm{Na}_{2} \mathrm{SeO}_{3}\right)$ solution of $8 \mathrm{mM}, 10 \mathrm{mM}$ and $12 \mathrm{mM}$ were mixed with fresh juice extracts and fresh peel extracts of Citrus paradisi and Citrus limonin a ratio of 2:1 (2-parts fruit extracts and 1-part sodium selenite solution) in separate beakers. The mixtures were then stirred on magnetic stirrer for 25-30 min to obtain a homogenous mixture. The $\mathrm{pH}$ was adjusted at 7 i.e., neutral. It was then subjected to orbital shaker at $70{ }^{\circ} \mathrm{C}$ in dark condition for $3 \mathrm{~h}$ at $200 \mathrm{rpm}$. After $3 \mathrm{~h}$ a slight color change was observed in all the sample mixtures and after $3 \mathrm{~h}$ the temperature was reduced to $37^{\circ} \mathrm{C}$ for $72 \mathrm{~h}$. After 3 days a strong color change was observed from pale yellow to brick red in all solutions. The sample tubes were then replaced from shaker to the incubator with same temperature condition. After further 2-3 days of incubation period the nanoparticles settled down at the base of the falcon tube $e^{12,21,22}$.

Antimicrobial activity analysis. Bacterial sample collection and inoculum preparation. Bacterial Samples were provided by the Institute of Molecular Biology and Biotechnology (IMBB), Bahauddin Zakariya University (BZU), Multan, Pakistan. Four Bacterial cultures, Escherichia coli (E. coli), Micrococcus luteus (M. luteus), Klebsiella pneumoniae (K. pneumoniae) and Bacillus subtilis (B. subtilis) were used to test the antibacterial activity of synthesized SeNPs. For bacterial inoculum preparation, nutrient broth was prepared and with the aid of sterilized wire loop, bacterial culture was taken and mixed in the sterilized nutrient broth. The inoculum was used after incubation of $24 \mathrm{~h}$ at $37^{\circ} \mathrm{C}$.

Agar well diffusion assay. Agar well diffusion assay was used for the evaluation of antimicrobial activity of synthesized SeNPs against bacterial pathogens. A $6 \mathrm{~mm}$ metallic borer was used for making wells. Ciprofloxacin was used as a standard drug for the assessment of antimicrobial activity.

Characterization of selenium nanoparticles (SeNPs). UV-vis spectrophotometer. A small aliquot of about $1 \mathrm{~mL}$ of the SeNPs of all the three concentrations i.e. $8 \mathrm{mM}, 10 \mathrm{mM}$ and $12 \mathrm{mM}$ was used for UV-Visible spectrophotometer analysis after intervals of $3 \mathrm{~h}, 24 \mathrm{~h}$ and $72 \mathrm{~h}$ in order to observe the reduction of Se ions in the reaction mixture. The maximum absorption at the relevant wavelength was noted. The wavelength was set between 100 and $800 \mathrm{~nm}(\mathrm{~nm})$ and the desired range to observe the peak for SeNPs was 300-800 nm. Double distilled water was used as a blank control in that analysis ${ }^{4,23-28}$. The spectrophotometer used for measuring the wavelengths of the SeNPs was PG instrument-t80 UV/Vis Spectrophotometer.

Sample preparation for further characterization. For sample preparation for further characterization tests of SeNPs, the nanoparticle mixture was subjected to repeat centrifugation for 3-4 times at 15,000 rpm for $20 \mathrm{~min}$. after every centrifugation the supernatant was discarded and replaced with deionized water. After final centrifugation, the sample tubes were placed upside down on a sterilized paper towel in order to remove any extra water inside the tube. After 5-10 min the nanoparticles were oven dried and solid nanoparticles were obtained which were further used for Characterization tests ${ }^{3,4,27}$.

Fourier transform infra-red (FTIR) spectroscopy analysis. Fourier Transform Infra-Red (FTIR) Spectroscopic studies were done using Bruker Germany Alpha FTIR spectrophotometer of Bahauddin Zakariya University, Multan, Pakistan ${ }^{27}$. FTIR analyses were done for the determination of the functional groups present at the surface of the nanoparticles that might be involved in the sorption process. The dried nanoparticle samples were diluted in potassium bromide $(\mathrm{KBr})$ solution. FTIR scan analysis range for the detection of the samples at peaks were between 1000 and $3500 \mathrm{~cm}^{-14,23,25,26,29,30}$.

Dynamic light scattering (DLS). For determining the size and morphological characteristics of the SeNPs, Zetasizer was employed. Zetasizer is used for the determination of three main properties of nanomaterials like its 
zeta potential, molecular weight and its size. The method by which the size of the nanoparticle is determined in Zetasizer is known as Dynamic Light Scattering (DLS). This procedure was carried out at $25^{\circ} \mathrm{C}$ using Zetasizer Nano S90. Those nanoparticles which showed maximum antimicrobial activity were used to measure the size via Zetasizer ${ }^{31,32}$.

Statistical analysis. The true experimental research design was used for performing the experiments. SPSS ver. 22 was used for analyzing the data. $\mathrm{p}<0.05$ was considered as significant.

Ethical approval. Experimental organisms were not used.

\section{Data availability}

All the other data that support the findings of this study are available from the corresponding author upon request.

Received: 6 May 2020; Accepted: 4 February 2021

Published online: 26 February 2021

\section{References}

1. Poole, C. P. Jr. \& Owens, F. J. Introduction to Nanotechnology (Wiley, Hoboken, 2003).

2. Anu, K., Singaravelu, G., Murugan, K. \& Benelli, G. Green-synthesis of selenium nanoparticles using garlic cloves (Allium sativum): Biophysical characterization and cytotoxicity on Vero cells. J. Clust. Sci. 28, 551-563 (2017).

3. Prasad, K. S., Patel, H., Patel, T., Patel, K. \& Selvaraj, K. Biosynthesis of Se nanoparticles and its effect on UV-induced DNA damage. Colloids Surf. B 103, 261-266 (2013).

4. Vyas, J. \& Rana, S. Antioxidant activity and green synthesis of selenium nanoparticles using Allium sativum extract. Int. J. Phytomed. 9, 634 (2017).

5. Jackson, T. C., Uwah, T. O., Ifekpolugo, N. L. \& Emmanuel, N. A. Comparison of antimicrobial activities of silver nanoparticles biosynthesized from some Citrus species. Am. J. Nano Res. Appl. 6, 54-59 (2018).

6. Husen, A. \& Siddiqi, K. S. Plants and microbes assisted selenium nanoparticles: characterization and application. Journal of nanobiotechnology 12, 28 (2014).

7. Rana, J. V. S. Synthesis of selenium nanoparticles using Allium sativum extract and analysis of their antimicrobial property against gram positive bacteria (2018).

8. Fisher, K. \& Phillips, C. Potential antimicrobial uses of essential oils in food: Is citrus the answer?. Trends Food Sci. Technol. 19, 156-164 (2008).

9. Nisha, S. N. et al. Lemon peels mediated synthesis of silver nanoparticles and its antidermatophytic activity. Spectrochim. Acta A Mol. Biomol. Spectrosc. 124, 194-198 (2014).

10. Aruoma, O. I. et al. Functional benefits of citrus fruits in the management of diabetes. Prev. Med. 54, S12-S16 (2012).

11. Fardsadegh, B. \& Jafarizadeh-Malmiri, H. Aloe vera leaf extract mediated green synthesis of selenium nanoparticles and assessment of their in vitro antimicrobial activity against spoilage fungi and pathogenic bacteria strains. Green Process. Synth. 8, 399-407 (2019).

12. Sharma, G. et al. Biomolecule-mediated synthesis of selenium nanoparticles using dried Vitis vinifera (raisin) extract. Molecules 19, 2761-2770 (2014).

13. Kapur, M., Soni, K. \& Kohli, K. Green synthesis of selenium nanoparticles from broccoli, characterization, application and toxicity. Adv. Technol. Biol. Med. 5, 2379 (2017).

14. Shende, S., Ingle, A. P., Gade, A. \& Rai, M. Green synthesis of copper nanoparticles by Citrus medica Linn. (Idilimbu) juice and its antimicrobial activity. World J. Microbiol. Biotechnol. 31, 865-873 (2015).

15. Tomotake, H., Koga, T., Yamato, M., Kassu, A. \& Ota, F. Antibacterial activity of citrus fruit juices against Vibrio species. J. Nutri. Sci. Vitaminol. 52, 157-160 (2006).

16. Sujitha, M. V. \& Kannan, S. Green synthesis of gold nanoparticles using Citrus fruits (Citrus limon, Citrus reticulata and Citrus sinensis) aqueous extract and its characterization. Spectrochim. Acta A Mol. Biomol. Spectrosc. 102, 15-23 (2013).

17. Kaviya, S., Santhanalakshmi, J., Viswanathan, B., Muthumary, J. \& Srinivasan, K. Biosynthesis of silver nanoparticles using Citrus sinensis peel extract and its antibacterial activity. Spectrochim. Acta A Mol. Biomol. Spectrosc. 79, 594-598 (2011).

18. Basavegowda, N. \& Lee, Y. R. Synthesis of silver nanoparticles using Satsuma mandarin (Citrus unshiu) peel extract: A novel approach towards waste utilization. Mater. Lett. 109, 31-33 (2013).

19. Rao, K. G., Ashok, C., Rao, K. V., Chakra, C. S. \& Rajendar, V. Synthesis of TiO2 nanoparticles from orange fruit waste. Synthesis 2, 1 (2015).

20. Dhanavade, M. J., Jalkute, C. B., Ghosh, J. S. \& Sonawane, K. D. Study antimicrobial activity of lemon (Citrus lemon L.) peel extract. Br. J. Pharmacol. Toxicol. 2, 119-122 (2011).

21. Bai, K., Hong, B., He, J., Hong, Z. \& Tan, R. Preparation and antioxidant properties of selenium nanoparticles-loaded chitosan microspheres. Int. J. Nanomed. 12, 4527 (2017).

22. Ramamurthy, C. et al. Green synthesis and characterization of selenium nanoparticles and its augmented cytotoxicity with doxorubicin on cancer cells. Bioprocess. Biosyst. Eng. 36, 1131-1139 (2013).

23. Yadav, J., Kumar, S., Budhwar, L., Yadav, A. \& Yadav, M. Characterization and antibacterial activity of synthesized silver and iron nanoparticles using Aloe vera. J Nanomed. Nanotechnol. 7, 2 (2016).

24. Kumar, S., Vazhacharickal, P. J., Mathew, J. \& Joy, J. Synthesis of silver nano particles from neem leaf (Azadirachta indica) extract and its antibacterial activity. J. Biotechnol. 4, 19-31 (2015).

25. Singh, K., Panghal, M., Kadyan, S. \& Yadav, J. P. Evaluation of antimicrobial activity of synthesized silver nanoparticles using Phyllanthus amarus and Tinospora cordifolia medicinal plants. J. Nanomed. Nanotechnol. 5, 1 (2014).

26. Rath, M., Panda, S. S. \& Dhal, N. K. Synthesis of silver nano particles from plant extract and its application in cancer treatment: A review. Int. J. Plant. Anim. Environ. Sci. 4, 137-145 (2014).

27. Sujitha, V. et al. Green-synthesized silver nanoparticles as a novel control tool against dengue virus (DEN-2) and its primary vector Aedes aegypti. Parasitol. Res. 114, 3315-3325 (2015).

28. Kouvaris, P. et al. Green synthesis and characterization of silver nanoparticles produced using Arbutus unedo leaf extract. Mater. Lett. 76, 18-20 (2012).

29. Kumar, B., Angulo, Y., Smita, K., Cumbal, L. \& Debut, A. Capuli cherry-mediated green synthesis of silver nanoparticles under white solar and blue LED light. Particuology 24, 123-128 (2016).

30. Mahdavi, M., Namvar, F., Ahmad, M. \& Mohamad, R. Green biosynthesis and characterization of magnetic iron oxide (Fe3O4) nanoparticles using seaweed (Sargassum muticum) aqueous extract. Molecules 18, 5954-5964 (2013). 
31. Dynamic Light Scattering (DLS): data acquisition and interpretation. In Polyion Complex (PIC) Nanoparticles for the Targeted and Passive Delivery of Antimicrobial Polymers and Peptides, 1 (1988).

32. Aljamali, N. M. Zetasizer technique in biochemistry. Biochem. Anal. Biochem. 4, 1 (2015).

\section{Author contributions}

G.B.A.: Prepared the nanoparticles and performed antibacterial activities. M.S.I.: Collected materials \& interpreted the data. M.M.S.G.: Performed Dynamic Light Scattering studies. A.H.: Performed Fourier Transform Infra-Red (FTIR) Spectroscopic studies. B.A.: Gave the idea, designed and write the manuscript. M.I.Q.: Directed and supervised the whole project.

\section{Competing interests}

The authors declare no competing interests.

\section{Additional information}

Correspondence and requests for materials should be addressed to M.I.Q.

Reprints and permissions information is available at www.nature.com/reprints.

Publisher's note Springer Nature remains neutral with regard to jurisdictional claims in published maps and institutional affiliations.

Open Access This article is licensed under a Creative Commons Attribution 4.0 International License, which permits use, sharing, adaptation, distribution and reproduction in any medium or format, as long as you give appropriate credit to the original author(s) and the source, provide a link to the Creative Commons licence, and indicate if changes were made. The images or other third party material in this article are included in the article's Creative Commons licence, unless indicated otherwise in a credit line to the material. If material is not included in the article's Creative Commons licence and your intended use is not permitted by statutory regulation or exceeds the permitted use, you will need to obtain permission directly from the copyright holder. To view a copy of this licence, visit http://creativecommons.org/licenses/by/4.0/.

(C) The Author(s) 2021 